\title{
Algunas reflexiones desde la acuarela de Mario Conde
}

\author{
Pamela Romano \\ Universidad Mayor de San Andrés
}

\begin{abstract}
This brief reflection on the work of Mario Conde begins by focussing on the special relationship the artist has with the technique of watercolor, exhibiting through that relationship an ethic based on copying. Out of that materiality, Conde builds his response to this moment in postmodernism in which art in general, and particularly Bolivian art, is developing given current social conditions. The ethic of copying is especially explored in two of his works: Exterminator Angel where appropriation addresses colonial issues that reappear in order to question and challenge the very notion of patria (homeland), and Drunk with power (Géricault in Los Andes) where the copy, adapted to the Andean world, distills a desire to reestablish the sacred and unique character of the work of art as well as the Andean imaginary.
\end{abstract}

\section{Keywords}

Andean baroque, Andean decolonizing patchwork, culture of simulacrum, ethics of copying, postmodern aesthetics, watercolor 


\section{Resumen}

Esta breve reflexión sobre la obra de Mario Conde se inicia poniendo atención en la relación particular que tiene el pintor con la técnica de la acuarela, desplegando a partir de esa relación una ética basada en la copia. Desde esa materialidad, Conde concretiza su respuesta al momento posmoderno en que se desarrolla el arte en general y el boliviano en particular, dadas sus condiciones sociales actuales. La ética de la copia es explorada especialmente en dos de sus obras: Ángel exterminador, donde la copia aborda temáticas coloniales que retornan para poner en cuestión y en entredicho la noción de patria, y Ebrios de poder (Géricault en Los Andes) en la que la copia adaptada a latitudes andinas, destila un deseo de restablecer el carácter sagrado y aurático de la obra de arte como del imaginario andino.

\section{Palabras claves}

acuarela, barroco andino, cultura del simulacro, estética postmoderna, ética de la copia, remiendo andino descolonizador

Pero... también el entusiasmo súbito tenía raigambres hondas, raigambres de carne viva pronta a ofrecerse en aras de aquella sublimidad excelsa: LA PATRIA.

Hilda MUNDY

\section{Nitidez}

La acuarela sería una técnica descreída y desencantada dadas sus condiciones materiales; el pigmento y el agua supondrían un movimiento de trazado y de lavado, de ida y vuelta, en "un ritmo sin solución de continuidad" ${ }^{1}$ más que en el rastro de una mezcla irresuelta -que se exhibe como

\footnotetext{
${ }^{1}$ Tomo esta cita del texto que leyó Marcelo Villena en la última exposición de Mario Conde en La Paz, donde expuso, entre otras obras, Ebrios de poder (Géricault en los Andes).
} 
rastro, entre colorida, entre acuosa. La acuarela en la tradición boliviana se habría hecho cargo de esto, mostrando esa discontinuidad entre el pigmento y el agua en el acuarelismo sobre todo paisajista. Los paisajes -aquellos paisajes cochabambinos, potosinos- mostraban sus maneras líquidas y acuosas, su superficie nostálgica, dando a relucir la apariencia de algo tercamente transparente, gaseoso, quizás ideal, quizás perdido, que emanaba de ese paisaje. La acuarela no era sino una disposición romántica. Un poco más acá, y como una variante próspera, la acuarela también se muestra como el reflejo de un sentimiento decididamente moderno donde las reflexiones e impresiones sobre categorías temporales hacen mella en la representación. El tiempo habitando la imagen, el tiempo haciéndose carne, hace pensar, por ejemplo, en la obra del acuarelista cochabambino José Rodríguez Sánchez, donde no sólo el tiempo se corporaliza, sino que muy andinamente se lleva como un q'epi pesado en la espalda; y claramente en la sólida obra de Ricardo Pérez Alcalá, quien hubiera modernizado el paisajismo y el bodegón, temporalizado los espacios luminosa, íntima y subjetivamente.

La búsqueda de la nitidez pareciera ser un uso inapropiado para la acuarela, en la medida en que buscaría la continuidad entre el pigmento y el agua, queriendo romper esa frontera contradictoria e inherente a la técnica, aunque enfatizándola más, descreyendo aún más de ésta. Desde aquí se podría entrever la obra del paceño Mario Conde y su postura sin duda crítica frente a la acuarela, dado que no sólo y desde la contradicción material va hacia la posesión de la figura nítida, sino que lo hace con lo que Marcelo Villena ha llamado un "gesto fotográfico".

Si las obras de Conde muestran esa posición y uso de la técnica, se entenderá que esto atañe directamente a la búsqueda misma de la obra, una obra que ya no persigue antologar el tiempo sino más bien trabajar sobre categorías espaciales. Por eso la nitidez en las acuarelas de Conde recae sobre el diseño, a manera de collage, a manera de patchwork, de espacios enfocados yuxtapuestos, donde el tiempo mismo se vuelve una categoría espacial. Pienso, por ejemplo, en una de sus obras más célebres, Pérez Velásquez, del 2000 (fig. 1), ${ }^{2}$ donde la lógica espacial permite la reunión de tiempos y perspectivas discontinuos aunque sincrónicos en aquellos personajes que habitan un bar de la ciudad de La Paz. El tiempo hecho espacio se ha hecho textualidad, por tanto es susceptible de reproducirse, citarse, plagiarse para integrar una tela hecha de otros tantos retazos, tal como sucede con Los borrachos o

\footnotetext{
${ }^{2}$ Las reproducciones de las obras de Conde se hacen con permiso del artista.
} 
El triunfo de Baco de Velásquez. ${ }^{3}$ Este gesto, basado en la nitidez de la copia, es el soporte ético y político desde donde Conde explora la acuarela nacional.

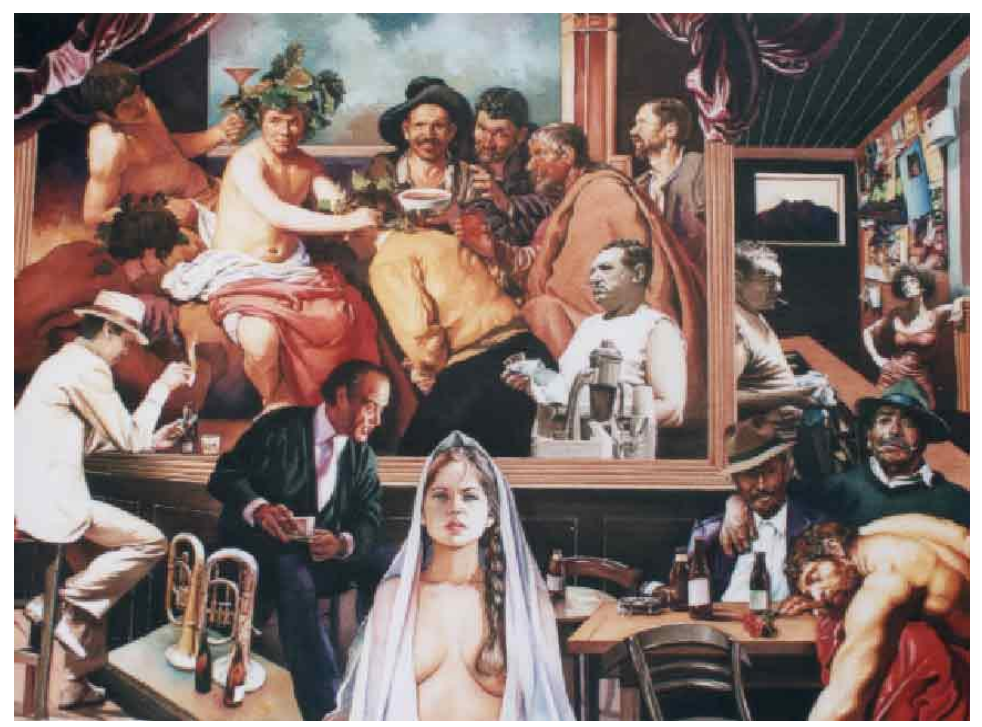

Figura 1. Pérez Velásquez, Mario Conde (2000)

Acuarela 50 x $70 \mathrm{~cm}$. Colección del autor

\section{Si la imagen es impostura}

Hay que entender el "gesto fotográfico" en la obra de Conde. Este gesto consiste en buscar replicar en y con la pintura acuarelista la imagen fotográfica, una imagen, sabemos, materialmente ubicada "entre la toma de la fotografía y la producción de la copia" (Belting 263); una imagen, en últimas,

\footnotetext{
${ }^{3}$ En su momento he explorado con más detalle esta obra en "Mío será el zumbido de esas moscas", publicado en la revista OtroArte (2008).
} 
indiferenciada de su medio técnico, de su aparato reproductor desproporcionadamente ajeno al hacer manual humano.

La imagen fotográfica no tiene que ver con el mundo natural: es un producto de la industria humana, un artefacto cuyo ser, en el sentido fenomenológico del término, no puede ser disociado de su significación histórica y del proyecto, necesariamente caduco, del que extrae su origen. Pero el rasgo característico de esta imagen es darse como el resultado de un proceso natural... Esta es la impostura constitutiva de la imagen fotográfica... (Damish 10).

Por lo pronto, la acuarela de Conde se posicionaría frente esa impostura naturalizada, posición cuyos principios recaerían en la copia del estilo fotográfico, el estilo de una imagen ontológicamente reproducible, esencialmente "objetiva" y por tanto antiestilística (Bazin), y que justamente por su precisión mimética-análoga posible por la máquina, habría destemplado el concepto de realismo en las artes plásticas a mediados y fines del XIX, para expandirse en el XX. El gesto fotográfico desde la acuarela en Conde, por eso, supondría ser algo así como un retorno, un volver en el tiempo para pronunciar varias preguntas en torno a la imagen, la relación con su referente $y$, sobre todo, su medio de producción, preguntas que vuelven y desde lo ex-contemporáneo de sus pinceles no dejan de tener un dejo de venganza arremetido contra y a favor de la imagen o, más puntualmente, contra y a favor de eso que llamamos realismo.

La pregunta dirigida al aparato es una pregunta hecha hacia la reproductibilidad técnica en una época ahora postmoderna, escandalosamente reproductible, donde lo aurático de la obra de arte, su "originalidad" (hoy por hoy extendida a cualquier obra, hasta la fotográfica), en general ha cedido en beneficio de espectáculos en la superficie de puras intensidades o, más precisamente y recordando a Jameson, simulacros de epidermis brillosa. Las preguntas de Conde desde la acuarela y sus propios brillos, elaboradas con lentitud y pacientemente dentro de la cultura del simulacro voraz y actual de la postmodernidad, tocan así el centro neural de ésta, siendo que no hacen sino preguntar sobre su ritmo, ese latido maquinal y acelerado, tecnológico, hambriento. Creo que en eso consiste el "gesto fotográfico" en la acuarela de Conde y su relevancia, gesto que imagino Benjamin bien hubiera celebrado. Esto porque Conde, además de formular sus preguntas desde el estilo de la imagen fotográfica, basa gran parte de su obra en la copia y reproducción de obras de la historia del arte universal. El aura en su obra se instala dada su búsqueda de historicidad manufacturada, revisión y revisita en el devenir histórico de la imagen a partir de la imagen, una revisión que desanda tácita y explícitamente la relación aurática en la obra de arte, 
haciendo su particular simulacro, sí, al fingir que en un momento la hubiera perdido y la hubiera vuelto a conquistar.

Entendiendo desde donde formula Conde estos gestos enfocados, desde un contexto social y político puntual del que es parte conscientemente, se puede entender que esa conquista no es sino una contraconquista, un contradiscurso, una suerte de desterritorialización para reterritorializarse en las prácticas artísticas latinoamericanas, bolivianas, andinas, que vienen exponiendo hace tiempo ya su deseo descolonizador.

Como dice Jameson, "resulta altamente apropiado que la cultura del simulacro nazca en una sociedad en que el valor de cambio se ha generalizado hasta el punto de que desaparece hasta el recuerdo del valor de uso, una sociedad de la que Guy Debord ha señalado, en una frase extraordinaria, que en ella "la imagen se ha convertido en una forma final de la cosificación para su transformación en mercancía" (Jameson 37-38). Conde vendría a arremeter contra estos principios básicos de la cultura del capitalismo tardío, promoviendo, por un lado, la "originalidad" destilada de la copia y, por el otro, construyendo su lugar de enunciación como un punto de interacción de espacios múltiples, heterogéneos, virtuales-actuales. Se puede imaginar en este trabajo horizontal, de epidermis y de superficialidad, sin embargo, algo rizomático, en la medida en que busca penetrar en la profundidad de la historia y desde ahí desplegarse. Su trabajo deja entrever por eso las figuras de un collage, de un patchwork, de una totalidad abierta hecha de parches, figura que en su momento deslumbró a otro paceño en esos sacos de aparapita, donde toda tela era posible de reunirse con otra para adquirir, decía Jaime Saenz, un solo color, el color del tiempo. Creo que para las acuarelas de Conde la unificación por el color temporal ya no es posible, siendo que le es imperioso mostrar y mantener la diferencia, resaltar nítida y enfocadamente la reunión de las diferencias. Su práctica particular en la acuarela pregunta incisivamente a una sociedad en cómplice y embriagadora amnesia, cada vez más limitada al ingreso responsable a la historia para convenir un presente y proyectar un futuro común -cosa que se ve muy claramente en lo más reciente de su obra, Ebrios de poder (Géricault en los Andes).

Si para la acuarela de Conde el pasado es un texto, su cita o copia recrudece en el presente para mostrar, por un lado, que el origen (la idea de una fundación) es un hecho confirmado y a su vez perdido; y por el otro, que existe una incapacidad generalizada de crear representaciones de nuestra experiencia actual (Jameson 42). Por eso su práctica, sus gestos, están absolutamente comprometidos con el proceso social contemporáneo boliviano. 


\section{El ángel de nuestra historia extermina}

El sustento histórico en la obra de Conde confiere una rememoración acerca de la "fundación", aquella que es confirmada y al mismo tiempo perdida, dado conceptos conciliadores como el "sincretismo" cuando nos referimos a la cultura boliviana. Por eso no es casual que Conde haga su entrada hacia la época colonial, ${ }^{4}$ se interese por ese escombro particular, cuando, al decir de Querejazu, se produce "el primer momento de un arte nacional" (Querejazu 13), - ¿acaso el momento de la "fundación" artística boliviana? - que, en general, se ha llamado "barroco mestizo". Adolfo Cárdenas, que desde la literatura explora esta veta barroca heredada, observa que:

[...] el colonialismo español, dada su categoría de heterogéneo, no es precisamente el modelo más secante en tramos comparativos. Asumiendo fielmente las modalidades de penetración católica, tiende a la mezcla, a la hibridez, considerando que la extracción de clase del grueso de la gente de la conquista, no tiene sangre que proteger, ni alcurnia que conservar. Este puede ser el probable origen de una propuesta que ha afectado y afecta el comportamiento estético del latinoamericano que se conoce como el 'Barroco mestizo', que tanto en su forma como en su contexto, si bien difiere acaso demasiado del barroco clásico, continúa siendo un exponente de la imposición del mundo occidental por sobre las culturas indioamericanas (Cárdenas 210).

Mario Conde parecería quedarse intranquilo con esta, diríamos, resuelta idea de "origen"; su ingreso a la historia se permite más o en verdad menos que eso: revelar de buenas a primeras una nacionalidad (¿una poesis?) frustrada, un estado inconcluso en el mismo centro que constituye el gesto patrio. Esta conciencia de farsa conveniente es acaso la fuerza que lo impulsa a sujetar el pincel y los colores para decidir pintar, que para Conde y su acuarela también supone dejar de pintar o, mejor dicho, enfocar un vacío.

La rememoración de lo perdido confirmado provendrá precisamente de un tema de la época (siglos XVII y XVIII): la iconografía de las series angelicales de, por ejemplo, Diego de la Puente, José López de los Ríos, el presunto maestro de Calamarca y posteriores pintores la mayoría anónimos, como se

\footnotetext{
${ }^{4}$ En 1992 Conde obtuvo el Gran Premio Salón "Pedro Domingo Murillo", con la acuarela El teatro de la conquista. Esta pintura es una de las más relevantes al mostrar la preocupación recurrente en Conde por enfocarse en los desechos históricos coloniales para cuestionar el presente; mostrar, diríamos, una aparente discontinuidad entre el tiempo de "origen" y el tiempo en que se vive, a la par de revelar las huellas de ese salto como el fundamento de su obra y, más allá, como el fundamento del presente habitable.
} 
nota en especial en la acuarela Ángel exterminador (fig. 2). ${ }^{5}$ Importante es apropiarse de este tópico pictórico siendo que en él se reconoce, otra vez, "un claro ejemplo del sincretismo cultural, en el que se representan las fuerzas de la naturaleza, personificándolas con ángeles, o manifestaciones del poder de Dios y más interesante aún, vestidos a la usanza de los capitanes tercios y caballeros del siglo XVII" (Querejazu 14). Conde al imitar el tema no deja de cuestionarlo y parodiarlo -el nombre mismo de la acuarela, homónimo al de una película de Buñuel, revela otra relación con el cristianismo y pone en crisis ese amistoso y benévolo sincretismo cultural.

En la acuarela encontramos, en segundo plano, un ángel desnudo con máscara, una espada en la mano derecha que posee decorados folclóricos y en la izquierda un animal que por su posición es difícil de reconocer, pudiendo ser un pescado o un camaleón. En primer plano se halla en el piso una máscara de Diablada y ya vencido -herido o muerto- el enemigo del ángel también desnudo. Al fondo se advierte una cruz que tiene por debajo o por encima algo así como un manto lítico indígena, claramente tihuanacota: es el Inti en presencia -aunque no a la vista, dado que el ángel le da la espalda y se interpone. El lugar donde se halla la cruz, por sobre y/o sub posición del sol, hace las veces de una puerta; en la parte superior de ésta, muy pequeña, aparece enmarcada la imagen del escudo de Bolivia incompleto, monocromático, con un gran y visible vacío.

El ángel de Conde es indiscutiblemente de sexo masculino y cubre pudorosamente sus partes púbicas. Dado que en la iconografía colonial "los seres celestiales son asexuados y se los representa barbilampiños, con cuerpo de adolescente y con faldellín corto, a veces con peto de armadura" (Mesa y Gisbert 100), se observan tres cambios drásticos respecto del tópico retomado: el ángel, además de ser un hombre maduro, está desnudo y posee, como único rastro de una posible armadura, una espada que porta en la mano derecha. El hecho de que sea un hombre revela que no es o que ha dejado de ser un ente alado; no es un otro del más allá, ni mucho menos carente de sexualidad definida; el ángel de Conde es mundano, forma parte de la terrenidad, es un ser caído. Aparece a la vista como un Adán avergon-

\footnotetext{
5 "Ángel exterminador" tiene varias versiones, varias reproducciones, en la obra de Mario Conde. Un interesantísimo despliegue de su ética basada en la copia que en este caso se adentra sobre sí misma. Cada reproducción, cada acuarela, no sólo merecería una lectura y escritura particular, sino que necesitaría entrar en relación con las otras para ver qué todo abierto se configura en esta(s) obra(s).
} 
zado, cubriéndose sus partes después de haber pecado y haber sido expulsado del Paraíso. Es un ángel apócrifo, un hombre muy bien disfrazado que se hace pasar por un ser alado. Existe, pese a todo, la conciencia de ese disfraz y caída y, quizás junto con ella, la destreza demasiado humana de disfrazar ese descenso. En el cuadro deambula pues el reconocimiento de la existencia de un simulacro, de una representación en la representación; el reconocimiento, ya en términos patrióticos, de la farsa que constituye el sincretismo.

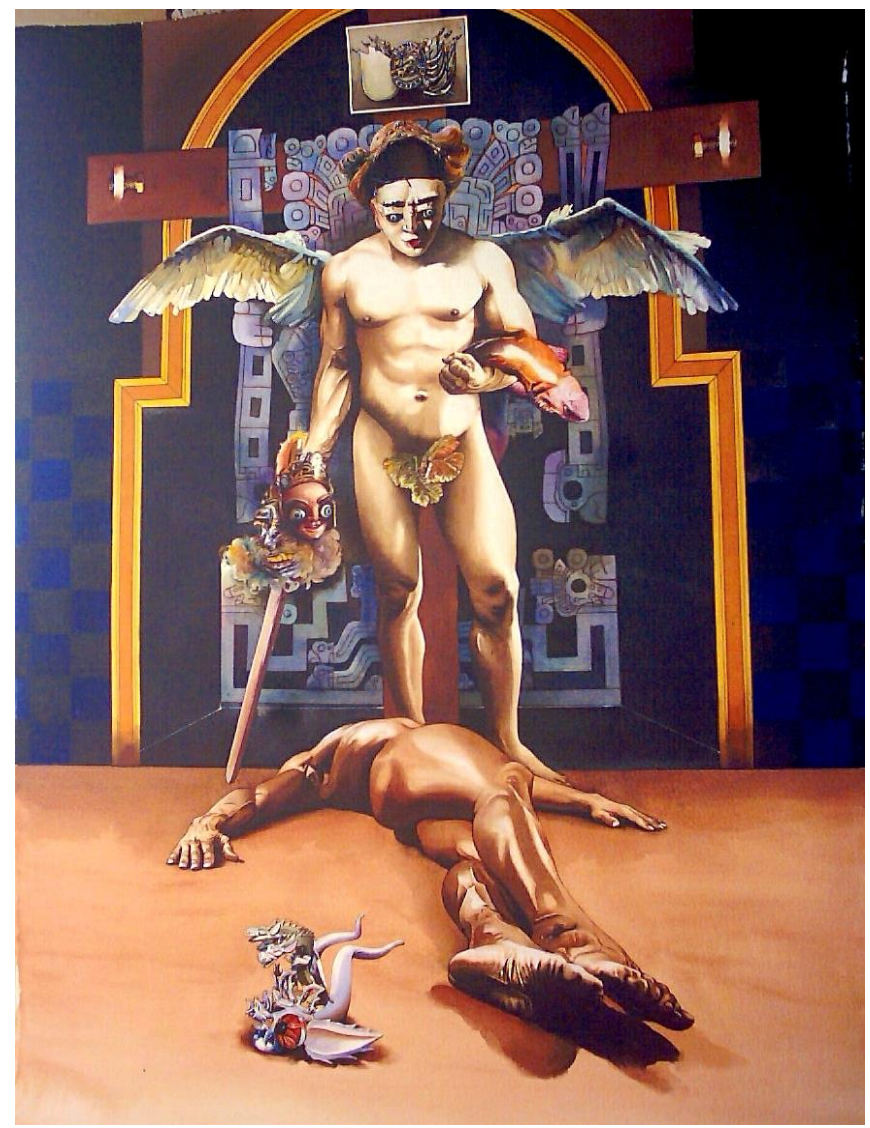

Figura 2. Ángel exterminador, Mario Conde (2005)

Acuarela $56 \times 76 \mathrm{~cm}$. Colección privada 
Recordaremos que es más o menos inusual que el opositor del ángel -que en las obras pictóricas virreinales, grosso modo, representa al refractario a los preceptos cristianos- forme parte del campo visual de la pintura. Uno de los casos conocidos es el cuadro Arcángel San Miguel (fig. 3$)^{6}$ del siglo XVII de Diego de la Puente, anterior a las series angelicales del Maestro de Calamarca. ${ }^{7}$ Además de que en ambos cuadros el opositor del ángel se halla desnudo a sus pies, vencido, ambos ángeles sujetan en la mano derecha una espada. En el caso del cuadro de de La Puente no resulta extraño siendo que se busca explícita y funcionalmente su representación (dada esa representación, precisamente, sabemos que es San Miguel) y ésta, por convención temática y de época, usaba la espada para caracterizar la destreza militar y el poderío de primer jefe de la milicia celestial.

Por su parte, Conde quiere representar a San Miguel pero doblando su representación. La búsqueda de representar al arcángel es la manera que tiene Conde de discurrir sobre la tradición pictórica colonial y la estratificación evangelizadora que supuso. A través de la copia-cita, el ángel se sitúa desde un lugar, además de revisionista, irreverente y simulado. Precisamente la simulación proviene de la máscara, tanto aquella que porta en el rostro, como la que lleva en la espada -su otro rostro- y aquella que está en el piso, cerca de su opositor caído. Es así que, además de haber una pretensión de poner en tensión la representación desde una revisión histórica, se convoque otro discurso, el de la Diablada, para así engrosar aún más los flujos de capas intertextuales.

La Diablada, que data más o menos de 1879 y es una suerte de culto a la Virgen de la Candelaria, pone en escena al Arcángel San Miguel, quien lucha a favor del bien, y a Lucifer y su escolta de diablos acompañados por sus seductoras mujeres llamadas "chinas supay", que haciendo uso de sus gracias tentadoras, abogan insistentemente por el mal (Balboa Bustamante 54, Villegas de Aneiva 225).

\footnotetext{
${ }^{6}$ Siglo XVII, óleo sobre tela, $198 \times 117$ cm, Museo Nacional de Arte, La Paz.

${ }^{7}$ Villegas de Aneiva considera que este cuadro "puede ser considerado como uno de los más importantes precursores de los de Calamarca y de los cuadros que fueron realizados posteriormente sobre el mismo tema. [...] Esta pintura data probablemente de alrededor de 1630 , como testimonia el hecho que otra tela de estilo comparable, San Feliciano, haya sido firmada y fechada en 1634" (2000: 149).
} 


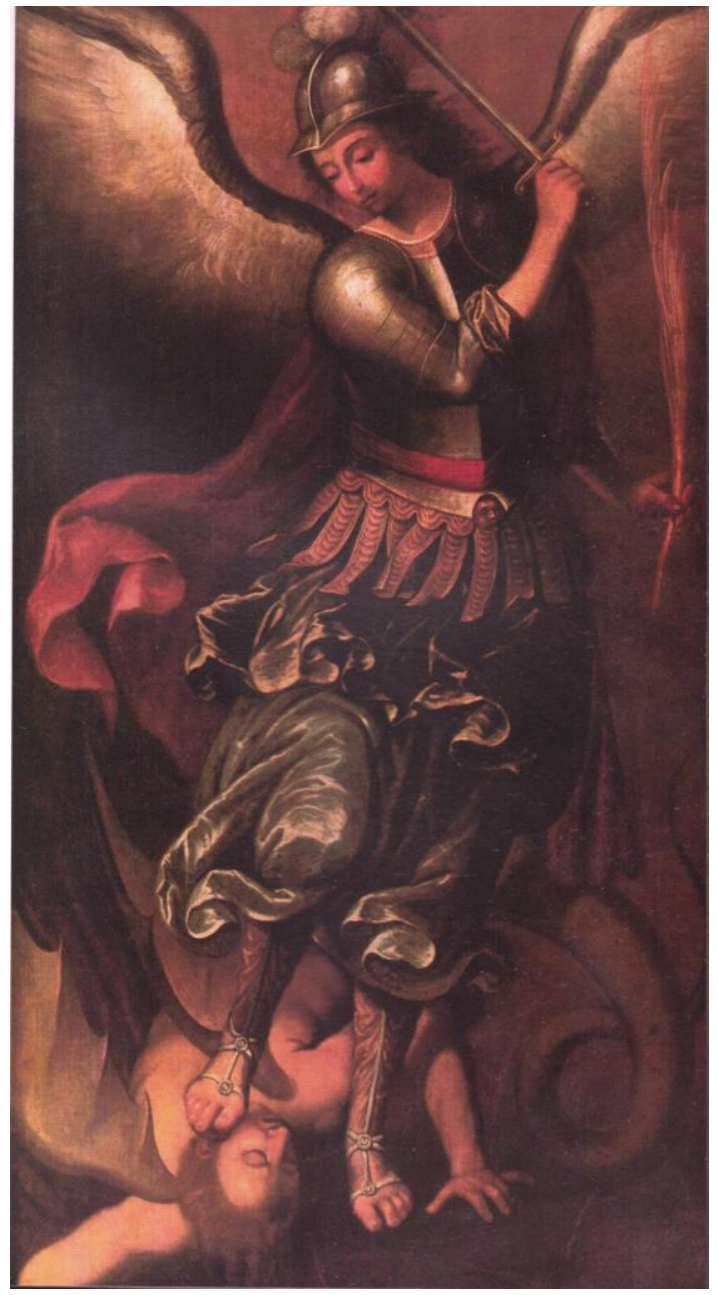

Figura 3. Arcángel San Miguel, Diego de la Puente (siglo XVII) Óleo sobre tela 1,17 x 1,98 cm.

Museo Nacional de Arte, Bolivia 
Convocar La Diablada en la acuarela no resulta arbitrario, pues se trata de un baile folclórico que para constituir los pasos y ritmos actuales de su danza, y originándose en una representación teatral, prolongaba y reforzaba el sentido fundante y dicotómico de las series angelicales pictóricas: aquella antigua y prolongada lucha entre el bien y el mal (Gisbert 243-245). En Ángel exterminador parecería discutirse este recorrido dada la copia-cita tanto al cuadro de Diego de la Puente, como al discurso de la Diablada a través de sus máscaras.

La lucha de San Miguel con los demonios fue un tema central para el teatro en la época colonial y su pensamiento, cuando la Diablada, todavía incipiente respecto a cómo la conocemos hoy, era solamente una danza de acompañamiento a la representación. En El paraíso de los pájaros parlantes, Gisbert sostiene que "la representación de la lucha entre San Miguel y los demonios era parte de muchas obras teatrales" (246). Se ha encontrado alguna escrita en quechua, lo cual muestra claramente a quién estaba dirigida y con qué fines:

[...] en Bolivia quedan dos versiones de esta obra recogidas por Julia Elena Fortún. Estas piezas tienen viejos antecedentes; uno de los más antiguos es el de 1601, cuando en las fiestas de Potosí en honor a la Virgen de Guadalupe aparece Lucifer, que entra a caballo con una carta que es leída públicamente, indicando que Proserpina, la diosa del infierno, que tenía aspecto de sirena, era la más hermosa. Un caballero, que representa a la Iglesia, enfrenta al demonio defendiendo a su vez a María como la más hermosa. Se acepta el reto en una misiva del jurado y finaliza la lucha entre el demonio y el caballero cristiano (Gisbert 243-244).

Otro texto, "Salvaje de Tarapaya", referido también por Gisbert, cuenta que el Inca se enfrenta a una dama que representa la Fe, quien pide que se cambie el sol por la cruz, logrando con esto que la lucha se desate entre el demonio y la Iglesia. Si bien el sol en esta pieza está identificado con lo demoníaco, en Potosí se lo ha identificado con el 'Tío' de la mina, y en general con todas "aquellas fuerzas naturales que bajo la advocación de diferentes dioses eran adorados en los Andes" (Gisbert 247).

Las obras teatrales, junto con su prolongación en la danza, dan testimonio sobre la manera en que ángeles y demonios "entraron en el imaginario del hombre andino" (Gisbert 247), testimonio que, desandando siglos y documentos, aparece en Ángel exterminador, donde Conde hace posible entrever esta pugna teatralizante vinculada a los "orígenes" de Bolivia -no por nada es autor de otra hermosa acuarela llamada El teatro de los descubridores, reproducida al final de este trabajo (fig. 4). 
Se entiende que el centro de este imaginario no sólo supone la antigua pugna sino el triunfo del "bien" sobre el "mal". Este triunfo, sin embargo, acarrea su fundamento teatral, mostrándose así falseado. No desde la historia sino más bien desde la vitalidad propia de la ficción. Rocha Monroy en su novela Potosí 1600 quizás pueda puntualizar mejor esto:

La Virgen [de la Candelaria] subió con sus propios pies las gradas del atrio y se posesionó del augusto lugar que le habían preparado, entre flores y ceras encendidas. La multitud oraba rosarios y letanías cuando irrumpió en el atrio el mismísimo Satanás vestido como centurión romano, con los ojos desorbitados, las fauces que echaban fuego, los cuernos tormentosamente retorcidos y un dragón arrimado al lomo que miraba fieramente a los fieles. Dio saltos ágiles sobre sus sandalias romanas, desplegó su capa donde mano diestra había bordado temibles imágenes del Averno y sacudió a la multitud con sus horrendos rugidos. Llamó entonces a su cohorte de mil demonios en medio de humos de colores vivos, y ellos y sus mujeres, que eran la tentación en persona, irrumpieron a paso de vencedores.

[...] Entonces se abrió paso entre la multitud San Miguel en figura alada, yelmo de plata ornado con plumas de colores celestiales, espadín y escudo del mismo precioso metal, y subiendo al atrio se propuso heroicamente hacer frente por sus solas fuerzas a esa legión de demonios. Se precipitó sobre ellos, pero lo recibieron con la fiereza que las plumas de sus alas volaban teñidas por los humos de colores, y a poco San Miguel, Policía de Dios, yacía maltrecho a los pies a la Virgen. Pero entonces se escucharon unos clarines que llegaban de la Plaza del Gato y se vio un resplandor que ahuyentaba las tinieblas e iluminaba con luz cenital las calles de Potosí. En medio de la confusión, los diablos no atinaban a distinguir el origen del tal prodigio, pero poco después apareció la primera escuadra de Arcángeles vestidos de libreas del más fino brocado francés y encajes de las mejores casas flamencas, borceguíes de cabritilla y un aire amariconado que confundía [...].

Las beatas rugían enloquecidas pidiendo pena de garrote y autos de fe y hogueras para los demonios que huían despavoridos en lo más oscuro de la noche, dicen que hasta Oruro y sin detenerse [...].

[...] La Mamita de la Candelaria no era ajena al festejo, lo mismo que los Arcángeles que en medio del regocijo general se confundían con demonios rezagados que no pudieron huir por el camino a Oruro y cruzaban aros y aros del ardiente líquido al punto de danzar juntos unas marchas que tenían un tanto de infernales y otro de celestiales (Rocha Monroy 47-49).

La disputa entre ángeles y diablos, que oscilan entre la teatralidad y su sobrante "real" en este pasaje de la novela, acaso prioriza -a desmedro de los rezos de las beatas- los aros aros propios de la fiesta indiferenciadora. La contrariedad entre el bien y el mal, dado el despliegue de los humos coloridos y contrastados en la noche potosina, así las cosas, aparece simulada e 
inconclusa. Y por la existencia misma de La Diablada sabemos que quien gana no es esa moralidad fundada en la básica dicotomía occidental, sino más bien una suerte de ética ficcional donde diablos y ángeles, en su contienda disfrazada, terminan bailando abrazados y comportan por igual las enajenaciones propias del Carnaval.

Un rasgo fundamental que diferencia el cuadro de Mario Conde con respecto al de Diego de la Puente y quizás el más radical, se funda en que, mientras que el arcángel San Miguel lleva en la mano izquierda una espiga de trigo, "una palma de victoria" (Villegas de Aneiva 149), el hombre que representa al ángel lleva un animal impreciso, que puede ser tanto un pescado como un camaleón. Me aventuro por la segunda posibilidad, en la medida en que el camaleón es un ícono que se repite constantemente en la obra condiana. A manera de los simbolismos utilizados en la pintura colonial, entonces, el ángel-hombre revela un estado mudable e inestable para la identidad, lo múltiple como tensión permanente y latente en el sujeto. Encarna, diríamos, la idea de una persistente metamorfosis del cuerpo, dando a entender que, pese a las máscaras, el verdadero disfraz es la piel misma. Así las cosas, la actitud y posición de Conde son radicalmente opuestas a las de las obras de las series angelicales coloniales: la dicotomía está exterminada desde su camaleonismo, estado abierto y movible del cuerpo a la pluralidad de lo diverso y, sobre todo posible a partir de su relación, distinción y entendimiento del espacio circundante.

Para este pensamiento lo que importa es el cambio continuo, la movilidad en lo inmóvil. Si se extermina algo es el lugar estático, cualquiera que sea éste, ni el "bien" cristiano, ni el "mal" indígena, como tampoco esa supuesta amistad sincrética: todo es acomodo temporal y según conveniencias espaciales. Adolfo Cárdenas acierta al observar que

En este contexto, y asumiendo la herencia de decenas de predecesores, [se entiende] el arte de Mario Conde o de Alejandro Salazar, artistas con la capacidad de revolucionar las temáticas típicas, con una clara tendencia a la crítica de poder desde todos los ángulos posibles, comenzando por la iglesia, madre del verticalismo; pasando por la instancias de poderío colonial, fundadora de la intransigencia del político criollo y terminando en el último individuo con delirios de grandeza (Cárdenas 211).

En un conocido cuadro de 1987 llamado Metamorfosis, podemos ver destrezas de la piel en la obra de Alejandro Salazar (fig. 5). Aquí efectivamente lo epidérmico supone un artificio en sí mismo por su versatilidad y predisposición al cambio, pero esa mudanza persigue un fin muy preciso: 
llegar a ser "gente", como se advierte en el último rostro femenino que cuanto más blanco se ha hecho, más ha contribuido a su diafanidad, alejado definitivamente, aunque conservando sus rasgos, del espesor oscuro de aquella chola que alguna vez fue. Este movimiento va hacia un lugar estático y de imposible retorno -lugar de borramiento. Por eso aquí la transformación, metamorfosis o cambio se entiende en términos de "progreso", sabiendo ya lo flexible y transigente de este concepto.

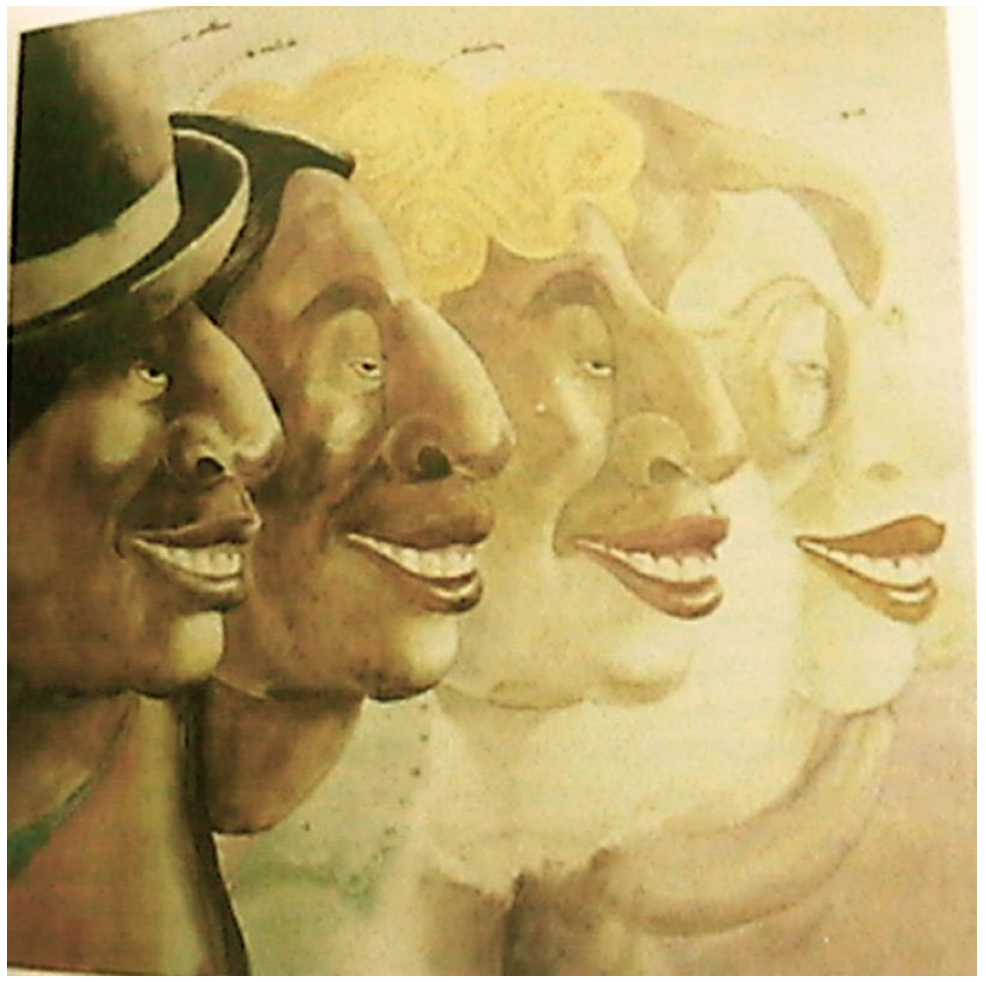

Figura 5. Metamorfosis, Alejandro Salazar (1987)

Acuarela sobre papel $40 \times 40 \mathrm{~cm}$. Obra destruida 
La lógica camaleónica de Conde supone algo parecido, pero sustancialmente distinto dada su sutileza: aunque es un cambio y/o una mudanza, hace que su movimiento sea intermitente por infinito, reconociendo que nunca existirá una piel cómoda donde estarse. Es la persistencia del disfraz, la empecinada búsqueda que no hallará otra cosa que no sea el reconocer que no hay piel o tez definitiva, configurándose como una búsqueda de una búsqueda, haciendo amagues a la pérdida.

De ahí el hacer consciente de un vacío, de un espacio faltado, de algo que nunca puede ni podrá llenarse: lo inconcluso del yo (patrio y artístico). Porque se notará que en el fondo de la pintura existe una cruz que vendría a ser la representación de lo cristiano, pero por encima o por debajo, a manera de una ilusión óptica, se encuentra la representación del Inti en la piedra o el telar. Esta ilusión, que no es otra cosa que un juego de perspectiva, es una avisada forma de figurar que vistas las cosas desde una determinada perspectiva uno de los dos cultos, aunque conviviendo, prima. Si la mirada se ocupa de la parte superior veremos que lo originario está por encima de la cruz pero, mirando abajo, a los pies y detrás del ángel-hombre, encontraremos su opuesto. Una tensión compleja, en ese sentido, que no se resuelve con esa idea de sincretismo, a la manera de ese baile que comparten ángeles y diablos en la novela de Rocha Monroy, en donde se evidencia que difícilmente vaya a ser resuelta entre tantos aros aros. Estamos, pues, frente a una tiesura de dos fuerzas opuestas que se jalan en su convivencia crítica; estamos frente a la imagen del escudo patrio republicano de una Bolivia, una nacionalidad, una identidad, faltada, incompleta, inconclusa, que lleva hondamente un vacío celebrado.

\section{Ebrios empoderados}

En el 2011 Mario Conde pinta Ebrios de poder (Géricault en los Andes) (fig. 6), una acuarela que se funda en la clara copia-cita al famoso cuadro de Géricault La barca de la Medusa, que se expuso por primera vez en el Salón de 1819 en París (fig. 7). Este cuadro de corte histórico supuso la ruptura con el neoclasicismo promulgado por la obra de David -dedicado a ensalzar a Napoleón y su poderío imperial- para abrir campo a lo que años más tarde se Ilamaría realismo, viendo sus pilares en Coubert y Daumier. El realismo buscado proviene de la referencia a un hecho concreto contemporáneo a la pieza, cuando una tripulación naufragó durante varios días en costas africanas, después de que los altos oficiales de la marina real francesa los 
hubieran abandonado a su suerte. En general, las lecturas que se han hecho de este cuadro coinciden en que expone de manera cruel y realista la decadencia del régimen borbónico, en una composición que tanto como exhibe la desesperación y la muerte sobre su base, levanta la fuerza de la vida con la esperanza de los sobrevivientes que a lo lejos parecen ver una salvación, quizás el puerto de Dakar. ${ }^{8}$ Sin menospreciar el contexto histórico del cuadro, quisiera detenerme en lo que pone en escena, que no es otra cosa que la relación cruenta entre los hombres de la balsa y la furia de la naturaleza, representada en el mar y el viento.

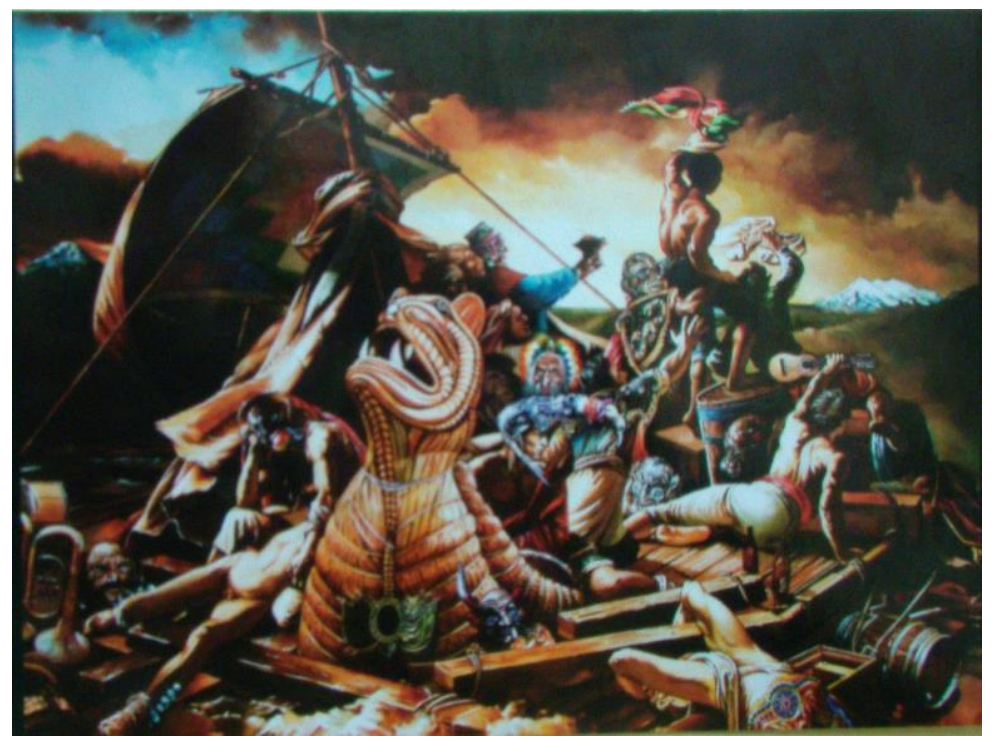

Figura 6. Ebrios de poder (Géricault en los Andes), Mario Conde (2011) Acuarela $56 \times 76 \mathrm{~cm}$. Colección privada

\footnotetext{
${ }^{8}$ Para una interprestación de este cuadro consultar Giulio Carlo Argan, El arte moderno 1770-1970 y Kenneth Clark, La rebelión romántica.
} 


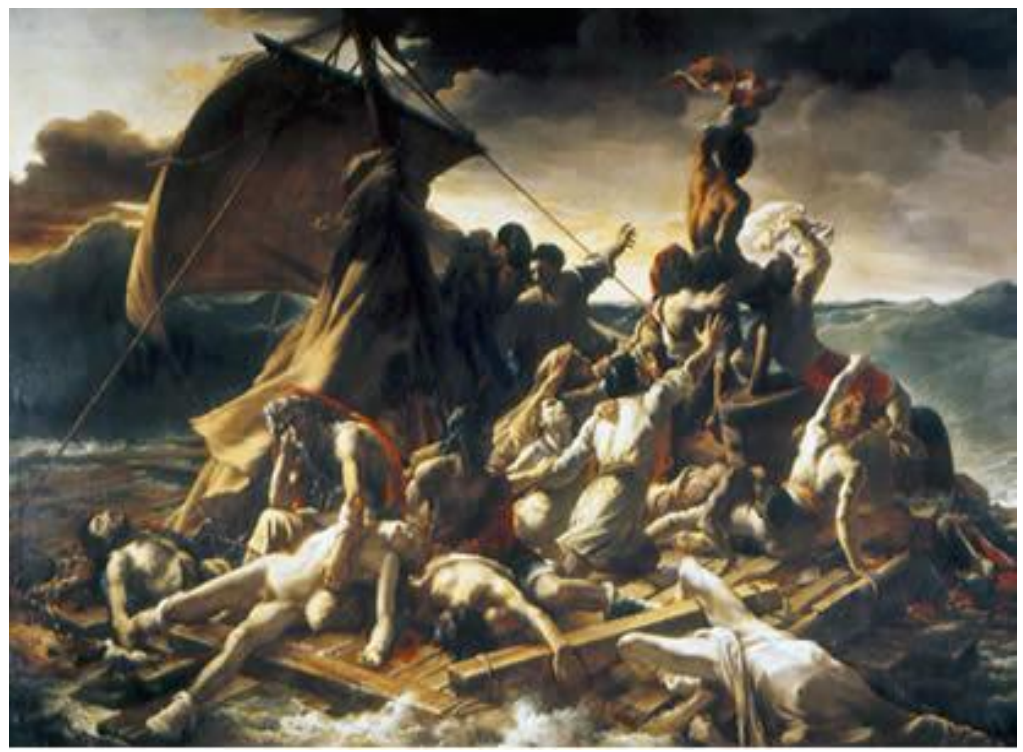

Figura 7. La barca de la Medusa, Théodore Géricault (1819)

Óleo sobre tela $491 \times 716 \mathrm{~cm}$.

Museo del Louvre

El hombre y la naturaleza se presentan como dos fuerzas enfrentadas en la disputa fundamental entre la vida y la muerte. Precisamente la pelea desatada y su resultado se exponen, aunque con decoro, en los cuerpos muertos y moribundos que sostienen el naufragio de la balsa, haciéndolo desde la base para que ésta se alce hacia la esperanza de la vida, una esperanza que se expresa y se eleva triangularmente, de manera equilibrada y armónica -dejos compositivos del neoclasicismo con fundamento aristotélico. El naufragio así se muestra intensa y pasionalmente: la contienda entre los hombres y la naturaleza se concretiza en un momento intenso, afectado, de pura "energía contenida". Esa contención es el aliento de este cuadro, su hálito es la tensión endémica sin posibilidad de resolución más que en el intervalo dramático de la inacción que padecen tanto las anatomías muertas, como las vivas, en aquellas costas irascibles. 
Conde copia la composición triangular, copia las fuerzas en tensión entre la base y la altura, y entre la profundidad de campo y el primer plano -esta tensión, llamémosla "horizontal", expresada en el viento que hincha vigorosamente la vela de la balsa en sentido contrario hacia donde los hombres sujetan la mirada y apuntan su esperanza. Pero añade en ese horizonte profunda y nítidamente al Illimani, y con esto creería que subvierte su referencia primera siendo que esa presencia de la montaña ni puede significar naufragio, y menos todavía aquel enfrentamiento romántico-naturalista entre la naturaleza y el hombre; en los Andes -bien puntualizado este espacio en el título de la obra- esa pugna parecería no existir, o de hacerlo, existir de otro modo; en los Andes la relación entre el hombre y su englobante natural es bien distinta.

El Illimani, como lo fue en su momento para Arturo Borda, no deja de ser central y persistente en la pintura de Conde, aunque su aparición ya no signifique ni enseñe "a mirar con hondura nuestra imagen, la imagen de nuestro mundo" (Saenz 1986, 119). En la pintura de Conde el Illimani se ha vuelto un ícono transportable, en tanto la representación icónica que se había hecho de él (figura 8). Está vaciado, roto y desvinculado de cualquier posibilidad y certidumbre mimética que aliente a la autorepresentación del ser boliviano, o más concretamente, del ser paceño y su imaginario. Asistimos a otro tipo de verosímil respecto al de Borda, de ahí que el Illimani en la obra de Conde siempre aparezca enmarcado, ya sea por una ventana, por un cuadro dentro del cuadro o, más interesante aún, por un marco de indistinción que oscila entre ventana y cuadro, discutiendo y problematizando conscientemente la representación dentro y sobre la representación. Enmarcado el Illimani es posible su transportabilidad, movilidad en el espacio; convertido en un marco contiene un vacío, es puro significante, afirmándose desde su negación a manera de un ceci n'est pas une pipe boliviano.

El Illimani en Ebrios de poder, si bien aparece sin marco -sin marco, a su vez, aparece la obra citada, sin mencionar el obvio, diferenciándose así de una obra como Pérez Velásquez, conserva esta ruptura propia de un hacer fundado en las categorías espaciales del parche y el collage, que en este caso particular, afecta su carácter sinecdótico respecto de la ciudad de La Paz. El Illimani está apartado de cualquier representación que no sea sí mismo, exponiéndose ahora y dado su vaciamiento en términos de presencia, una presencia que es lejana-cercana, pequeña-grande, profunda-nítida, en aquel 


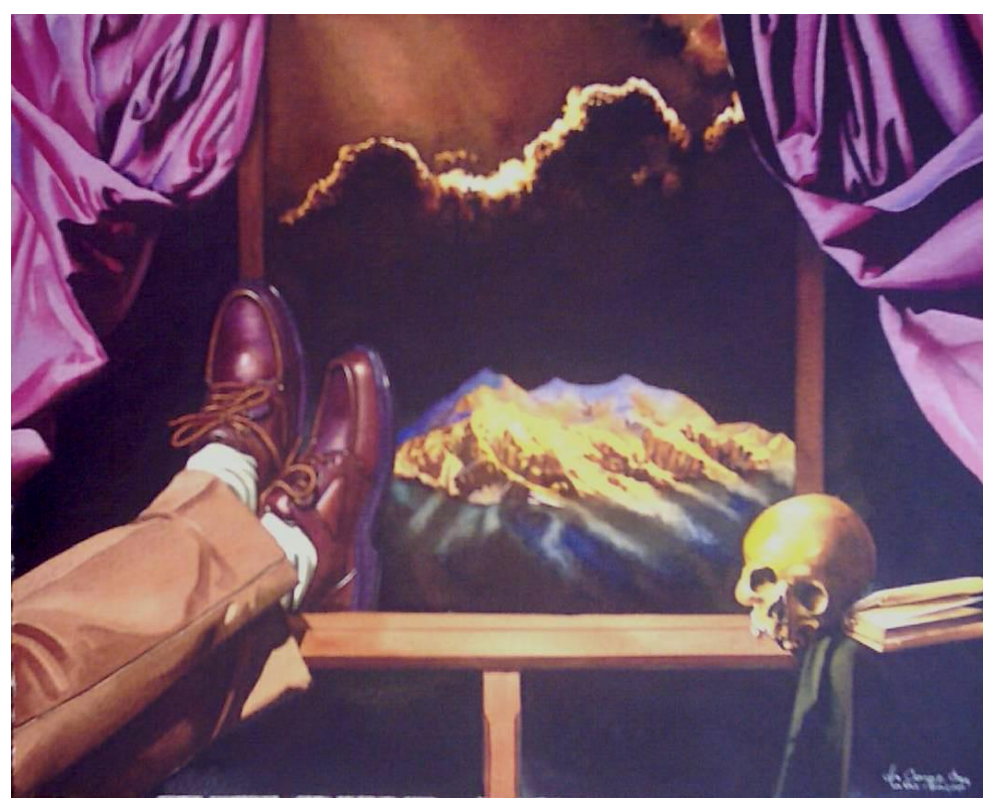

Figura 8. Sin título (“Illimani”)", Mario Conde (2004)

Acuarela $28 \times 38 \mathrm{~cm}$. Colección privada

horizonte hacia donde miran los sujetos andinos desde su balsa de totora. Sin marco ni representación, conservando su ruptura respecto del espacio referencial, es una presencia neta que mira desde el horizonte. Y esto recoge un saber antiguo que conservan los moradores de los Andes, quienes saben que "no es la montaña lo que se mira... Es la presencia de la montaña" (Saenz $1979,17)$. Con lo que en Ebrios de poder se estaría poniendo en escena el restablecimiento del carácter sagrado de la montaña, esa presencia que se percibe como espíritu del lugar, como el Achachila que es, auscultando él a los hombres.

Y el ambiente sagrado, con vistas a reestablecerse, circula por todo el cuadro; los hombres parecen navegar en el lago Titicaca, lago sagrado desde tiempos inmemoriales, de donde habrían emergido, sabemos, la pareja mítica de Manco Kápac y Mama Occllo y todas sus enseñanzas; la balsa de totora tiene una terminación zoomorfa con rostro de felino, remitiéndose al Puma o Titi, animal sagrado y tótem para la cosmovisión andina; otro Achachila, 
esta vez desde el lado izquierdo -presumiblemente el Illampu-contempla también a los hombres, y aparece, en lugar de vela para la navegación, la wiphala flameante del Kollasuyu. Todos estos elementos sagrados entran en relación con la tripulación kolla que parecería querer recogerse de una borrachera de largo aliento, alzarse hacia aquel horizonte donde se deja ver el Illimani. El triángulo para la composición neoclásica se eleva aquí adaptándose a ese deseo y propósito, que pasa, por ejemplo, por un charanguista que alza su instrumento con euforia. Ya en sus alturas, como último y necesario peldaño para llegar a esa cima equilibrada, aparece un yatiri que levanta su sahumerio a manera de ofrenda, práctica tanto solemne como primordial para entablar relación con el Illimani; éste, a su vez, no solamente se encuentra frente al hombre sino que a su misma altura, enfatizando con esto su presencia tan lejana como próxima, su carácter sagrado. Estos dos componentes del cuadro, el yatiri y el Illimani, poniendo en escena el ritual andino sólo a través de su relación, permiten compositivamente que un hombre joven pueda alzarse, levantar el brazo con unas telas que llevan los colores de la bandera boliviana, pero antes incluso, los de la kantuta. Aquí la esperanza se tiñe de estos "pigmentos naturales", se promete y se bate como proyecto a los ojos de la deidad. Quizás ésta sea la puesta en escena de la devoción, apartada y recogida de los sobrantes de la fiesta profana.

Es que este cuadro pareciera "alzarse" y así marcar, creería, una nueva etapa en la obra de Conde. Sobre la base inestable del cuadro se posicionan la borrachera y las máscaras folclóricas de las que ya algo he discurrido, queda la banda con sus bombos y trompetas, las cervezas y los aros aros, y junto a esa temible fiesta, aquel escudo monocromático e incompleto de Bolivia. El alzamiento se da a partir de esta plataforma ya vista en acuarelas pretéritas. El cuadro se alza, añadiendo más tensiones respecto al de Géricault, que tienen que ver con los desvelos propios de Conde y también con la concepción del espacio para el andino.

Al alzarse se establece una relación entre un arriba y un abajo, expresada como una tensión opuesta y complementaria entre lo sagrado y lo profano -lo sagrado vinculado a lo natural y lo profano a la fiesta. Desde allí se discute Bolivia -estado plurinacional- siendo que arriba además está la tricolor y abajo el escudo; la discusión es ampliada desde cuestiones y elementos también opuestos y complementarios propios a la pintura, como lo son el dibujo -para el escudo republicano- y el color -para las telas que imitan tintes naturales. El arriba y el abajo también suponen una tensión irresoluble y de convivencia para los hombres, expresada en los pigmentos de sus pieles 
-lo cual recuerda y problematiza otra vez al cuadro de Salazar- avisando la posición de debajo de los $k^{\prime}$ aras y la de arriba de los t'aras.

Este alzamiento tricolor creería que inaugura un nuevo eje en la obra de Conde. Claramente esto no está desvinculado del proceso que vive Bolivia desde la asunción al poder de Evo Morales, quien está representado de perfil oscuro en la acuarela. Como lo hacía Géricault, Conde entabla conversación crítica y directa con su tiempo inmediato, pero lo hace desde la cita-plagio, ética que le permitiría, al mismo tiempo de responder a su contemporaneidad, diluirla. Esto porque, siguiendo las reflexiones de Jameson, lo que hace la práctica del pastiche no es sino dotar a la realidad actual y a la historia presente "del hechizo y la distancia de un satinado espejismo" (Jameson 35). Escribe este teórico:

Pero este propio modo estético, con su poder hipnótico, surgió como síntoma elaborado de la mengua de nuestras historicidad, de nuestra posibilidad vital de experimentar la historia de manera activa: por tanto, no se puede afirmar que produzca este extraño ocultamiento del presente por su propio poder formal, sino sólo que lo hace con el fin de demostrar, mediante estas contradicciones internas, la enormidad de una situación en la que parecemos ser cada día más incapaces de crear representaciones de nuestra propia experiencia actual (Jameson 35).

El espejismo promulgado por la copia-cita, así la cosas, supondría una incapacidad representacional, pero hay que entender que en latitudes bolivianas el espejismo y la distancia antes bien, son fundantes y son aquellas que se han impuesto sobre el indio, sobre su imaginario, sobre su cosmovisión. Por eso no es menor en la acuarela poner en escena el deseo de querer reestablecer el carácter sagrado de varias entidades andinas, mostrando que su reestablecimiento depende de la mirada, de la lectura, del grosor del espejismo. La presencia de la wiphala en su adaptación como vela de la balsa desde este punto es relevante y afirmante en su contradicción. El viento, aunque se opone a la dirección que toman los hombres, hincha la wiphala y pareciera restablecerla también, recordando que dada su etimología significa "voz de triunfo flameante". 


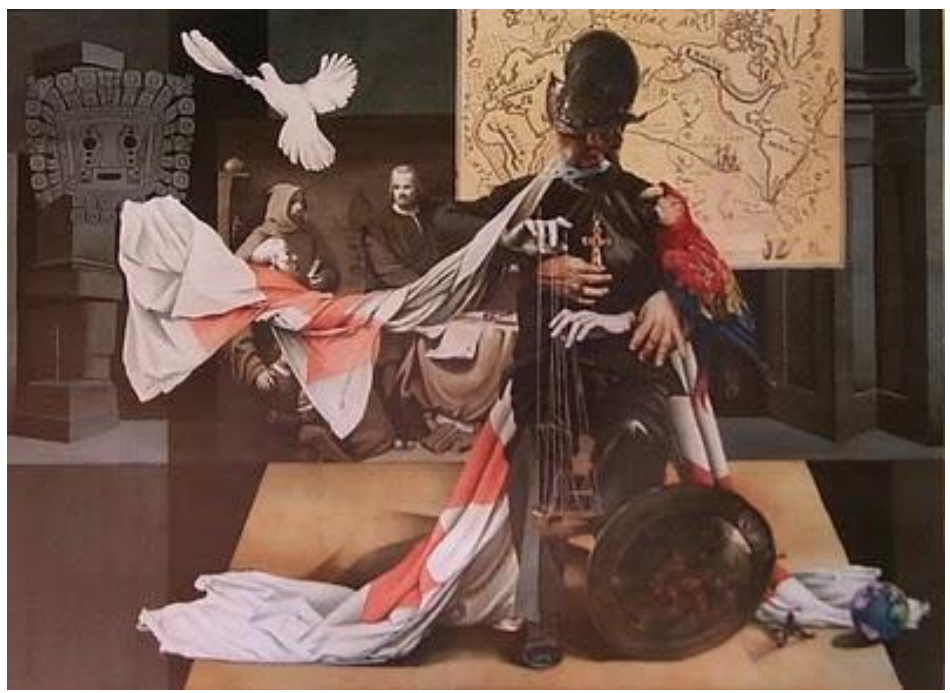

Figura 4. El teatro de los descubridores, Mario Conde (1992)

Acuarela $57 \times 76 \mathrm{~cm}$.

\section{Bibliografía citada}

ARGAN, Giulio Carlo. 1976. El arte moderno 1770-1970. Valencia: Fernando Torres.

BALBOA Bustamante, Esther. 2004. "Carnaval de Oruro, carnaval de Bolivia”. Entre ángeles y diablos. Antonio Suárez y Antonio Cisneros, eds. La Paz: I: CAF, Boboce, Banco Sol. 21-29.

BAZIN, André. 2008. “Ontología de la imagen fotográfica”. ¿Qué es el cine? José Luis López Muñoz, trad. Madrid: Rialp.

BENJAMIN, Walter. 2004. Sobre la fotografía. J. Muñoz Millanes, ed. y trad., Valencia: Pre-textos.

${ }^{9}$ Con esta acuarela Mario Conde ganó el Gran Premio del XL Salón Pedro Domingo Murillo, 1992. Dos años después Enrique Dussel ilustró la portada de la edición boliviana de 1942 El encubrimiento del otro precisamente con esta acuarela. 
BELTING, Hans. 2007. "La transparencia del medio. La imagen fotográfica". Antropología de la imagen. Buenos Aires: Katz editores. 263-296.

CÁRDENAS, Adolfo. 2002. "Arte de sátira y grotesco social”. Propuestas y tendencias del arte boliviano a fines del milenio. Denise Ostermann, comp. La Paz: Artes Gráficas Latinas. 209-212.

CLARK, Kenneth. 1990. La rebelión romántica. Bernardo Moreno Carrillo, trad. Madrid: Alianza Forma.

DAMISCH, Hubert. 2008. El desnivel. La fotografía puesta a prueba. Buenos Aires: La Marca.

GISBERT, Teresa. 1999. El paraíso de los pájaros parlantes. La imagen del otro en la cultura andina. La Paz: Plural.

JAMESON, Fredric. 1991. Ensayos sobre el posmodernismo. Esther Pérez, Christian Ferrer y Sonia Mazzco, trads. Buenos Aires: Imago Mundi.

MESA, José de y Teresa Gisbert. 1977. Holguín y la pintura virreinal en Bolivia. La Paz: Juventud.

QUEREJAZU, Pedro. 1989. "La pintura boliviana del siglo XX". Pintura boliviana del siglo XX. La Paz: Ediciones INBO. 13-32.

ROCHA MONROY, Ramón. 2002. Potosí 1600. La Paz: Alfaguara.

ROMANO, Pamela. 2008. "Mío será el zumbido de esas moscas". OtroArte. 1. 4152.

SAENZ, Jaime. 1986. Vidas y muertes. La Paz: Huayna Potosí.

---. 1979. Imágenes paceñas. La Paz: Difusión.

VILLEGAS DE ANEIVA, Teresa. 1996. "Arcángel San Miguel”. El retorno de los ángeles. El barroco de las cumbres en Bolivia. La Paz: Unión Latina. 225.

VILLENA, Marcelo. 2012. Comentarios a la última exposición de Mario Conde en La Paz. Galería Altamira.

[http://www.altamiragaleria.com/index.php?controller=exposiciones\&action =viewDetalle\&i=28] página descargada el 15 de diciembre, 2012.

\section{$(C))$ BY-NG-ND}

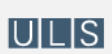

This work is licensed under a Creative Commons AttributionNoncommercial-No Derivative Works 3.0 United States License.

This journal is published by the University Library System of the University of Pittsburgh as part of its D-Scribe Digital Publishing Program, and is cosponsored by the University of Pittsburgh Press. 